\title{
Intelligence and Stupidity
}

\section{-The Educational Power of Cipolla's Test and of the "Social Wheel"}

\author{
Piero Mella \\ Department of Economics and Management, Pavia University, Pavia, Italy \\ Email: piero.mella@unipv.it
}

How to cite this paper: Mella, P. (2017). Intelligence and Stupidity. Creative Education, 8, 2515-2534.

https://doi.org/10.4236/ce.2017.815174

Received: November 29, 2017

Accepted: December 24, 2017

Published: December 27, 2017

Copyright $\odot 2017$ by author and Scientific Research Publishing Inc. This work is licensed under the Creative Commons Attribution International License (CC BY 4.0).

http://creativecommons.org/licenses/by/4.0/

\begin{abstract}
This paper will present the model Carlo Cipolla developed in his worldwide best-selling essay on "The Basic Laws of Human Stupidity" along with the framework of social behaviors it contains. Cipolla did not intend to explore intelligence but to focus primarily in his analysis on stupidity, two characteristics of the social behavior that man, as an individual or group agent, can reveal when he interacts in social groups and organizations of all types and sizes. More generally, Cipolla put forth a simple framework that classified the behavior of the man/actor in a social or organized group based on the advantages and disadvantages such behavior brought to the actor and the group of which he is a part. According to the author, all group individual behavior can be qualified according to two parameters: 1) advantages or disadvantages to the actor, and 2) advantages or disadvantages for "others". The combination of these parameters produces the four individual types: 1) Intelligent people, 2) Helpless/Naive people, 3) the Bandit and 4) the Stupid person. This general outline is so simple that it represents a powerful and effective educational tool to make people aware of how they can be guided when they interact with other individuals. Therefore, Cipolla's book is used in schools, universities and training courses for managers to send an educational message: behave intelligently and avoid stupidity, because "the Stupid person is more dangerous than the Bandit". This study seeks to demonstrate that when a third parameter is introduced-The volition or lack thereof of the actor to cause advantages to others-four other types of individual can be added to Cipolla's original typology: 1) the Able or Capable person, 2) the Hero, 3) the Incapable person, and 4) the Egoist. These eight types can be represented in a circular model that I have termed the Social Wheel, which increases the educational power of Cipolla's idea. The paper will show that "the Incapable person is more dangerous than the Stupid one".
\end{abstract}




\section{Keywords}

Intelligence, Turing's Test, Stupidity, Cipolla's Test, Social Wheel, Bandit, Incapable Person

\section{Introduction: Recognizing Intelligence}

In their book Intelligent Behavior in Animals and Robots, David McFarland and Tom Bösser recognize that Intelligence is a relative, elusive, multi-faceted concept:

[...] definitions of 'intelligence' vary with the theoretical position (and also the political persuasion of the definer. The biologist tends to stress concepts such as healthy adaptation, capacity for adjustment to the environment, and learning to learn. The more philosophically minded intellectual is liable to emphasize the element of abstraction... the capacity for abstract thought." The computer engineer, interested in artificially intelligent machines, may focus on capabilities of the machine that make its performance difficult to distinguish from human performance (Turing, 1950). In humans, it seems (from introspection) that cognition involves symbolic reasoning (McFarland \& Bösser, 1993: 21).

There are other dimensions of intelligence which focus on the identification the characteristic of "being intelligent" allow us to assume:

Intelligence, as defined in standard dictionaries, has two rather different meanings. In its most familiar meaning, intelligence has to do with the individual's ability to learn and reason. It is this meaning which underlies common psychometric notions such as intelligence testing, the intelligence quotient, and the like. In its less common meaning, intelligence has to do a body of information and knowledge. This second meaning is implicated in the titles of certain government organizations, such as the Central Intelligence Agency in the United States, and its British counterparts MI-5 and MI-6. Similarly, both meanings are invoked by the concept of social intelligence $[\cdots]$ referring to the person's ability to understand and manage other people, and to engage in adaptive social interactions. More recently [...] social intelligence [is used] to refer to the individual's fund of knowledge about the social world (Kihlstrom \& Cantor, 2000).

We can start by asking ourselves if it is possible to identify some criterion, or test, to define a given entity, man, animal, machine, autonomous robot, or alien visitor, as intelligent not only for its way of being but for the quality of its behavior. Without exploring the rich and complex world of behaviorism we can recognize intelligence by considering two "behavioral dimensions", which, even though they do not consider any hypotheses on the cognitive instruments and processes that allow one to recognize an individual (agent) as intelligent, are 
useful in understanding the behavioral model I have termed "The Social Wheel" (Section 5):

1) Intelligence as an attribute of the communicative behavior of an individual acting as a cognitive agent;

2) Intelligence as judged by the effects produced by social behavior in terms of the advantages and disadvantages it generates.

This study will examine in depth point (2) by investigating the conceptual framework Carlo Cipolla suggested. Two objectives are set forth: to pay homage to the deceased scholar by sharing his ideas; second to introduce a broader framework integrating the typology proposed by Cipolla. I shared my ideas with Carlo Cipolla and, in keeping with the spirit of "Cheerful But Not Too Much" (his larger work), I believe that the broader framework can be fully incorporated into the original one. Nevertheless, it is useful to briefly examine the first dimension point (1) as a premise for a better understanding of Cipolla's model and the concept of stupidity, which is the opposite of intelligence, and subsequently an understanding of "The Social Wheel" model.

The paper is structured in three relatively autonomous parts, connected in a single reading path:

- Section 2, examination of some definitions of intelligence.

- Section 3, presentation of the Stupidity test by Carlo Cipolla.

- Section 5, proposal of the "Social wheel" model as an extension of Cipolla's conceptual framework.

\section{2. "Intelligent" Communicative Behavior. Some Definitions and Turing's Test}

To explore the concept of intelligence regarding the actor's communicative behavior with others, we must consider two concepts:

1) Intelligence as a characteristic of thinking a person would normally display during communicative behaviour in linguistic interactions;

2) Intelligence as the mental capacity to think efficiently in interacting with people and the outside world.

These concepts raise problems, which are so large and complex as to require for their investigation entering the increasingly extensive worlds of Cognitive Science, Psychology and Artificial Intelligence, which is beyond the scope of this paper. This section will merely present some aspects of intelligence.

The first is the question: "How can we recognize intelligence", understood as intelligent thinking. I shall mention two approaches, one by the mathematician Alan Turing, the other by the biologists Humberto Maturana and Francisco Varela.

According to Turing, who needs no introduction, intelligence is typical of human interactions; therefore, limiting ourselves to linguistic interactions, we can define intelligence as the ability to communicate "as" a human being; or, better yet, the inability to recognize that an "agent" communicating with a hu- 
man being is "not human", an animal, a machine, artificial intelligence, or an extraterrestrial. The great mathematician thus conceived of a simulation test: the well-known "Turing's Test”.

The original version of the test from the 1950 essay Computing Machinery and Intelligence was described as follows by Turing himself:

I propose to consider the question, "Can machines think?" [‥] The new form of the problem can be described' in terms of a game which we call the "imitation game". It is played with three people, a man (A), a woman (B), and an interrogator $(\mathrm{C})$ who may be of either sex. The interrogator stays in a room apart from the other two. The object of the game for the interrogator is to determine which of the other two is the man and which is the woman. He knows them by labels $\mathrm{X}$ and $\mathrm{Y}$, and at the end of the game he says either " $\mathrm{X}$ is A and $\mathrm{Y}$ is B" or " $\mathrm{X}$ is B and $\mathrm{Y}$ is A" (Turing, 1950: 433).

Leaving out the technical aspects and generalizing somewhat, Turing's Test can be described as follows: if we do not consider the physical aspect of communicating entities (let us place the entity whose intelligence we wish to evaluate in an isolated room with only the possibility of communicating via computer), an entity can be defined as intelligent if, by conversing with it as long as we desire on whatever argument we choose, we cannot distinguish it from a human being. This is a powerful yet simple test, one based on the assumption: the only intelligence whose existence we can prove must be similar to human intelligence.

In his famous volume The Oxford Companion to the Mind, the neuropsychologist Richard Gregory (1987), stated that the imitation game proposed by Alan Turing is "the best test available for confirming the presence of intelligence in a machine [and thus in men and animals]".

What can we say about the emotional component of intelligence? Reflecting on the emotional component of intelligence, the neurosurgeon Geoffrey Jefferson criticized the Universal Machine conceived of by Turing (a criticism subsequently refuted by the latter) in a 1949 work entitled The Mind of Mechanical Man:

Not until a machine can write a sonnet or compose a concerto because of thoughts and emotions felt, and not by the chance fall of symbols, could we agree that machine equals brain - that is, not only write it but know that it had written it (Jefferson, 1949: 1110).

For the Chilean biologists Humberto Maturana and Francisco Varela, intelligence must be observed or inferred as the capacity of an individual (or an autonomous system) to adapt to other individuals' behavior or to "the events in life", emphasizing the deceptive aspect of attributing emotions to other individuals, taking these for intelligence or the lack thereof, just as we normally do when we say that "the other day we rode a wonderfully frisky horse" or that "the only thing our dog can't do is speak". In this sense, John Mingers explicitly recognizes 
the fundamental role of structural coupling in defining intelligent behavior in his book Self-Producing Systems: Implications and Applications of Autopoiesis.

$[\cdots]$ intelligence is normally seen as an objective property of a person or animal, like weight or strength, which can be measured in an objective way by, for example, solving problems or puzzles. Maturana argues that we must ask how behavior which observers call intelligent is generated. His answer is that it must be the result of a history of structural coupling with the environment and/or other organism, and that therefore any behavior that is successful within a domain of structural coupling is intelligent behavior. Intelligent is neither a property of the organism, or some part of the organism, nor is it direct observable. The word intelligence connotes the structure resulting from coupling in various domains and it is only manifest in particular instances of coupled or consensual behavior (Mingers, 1995: 77).

A question arises: how intelligent are wolves or lions that hunt in herds, or bees which, by gathering pollen, produce the pollination that will allow flowers to bloom again, from which pollen can again be gathered, or the schools of sardines that group together into "camouflaged figures", randomly formed, in order to frighten aggressors or defend themselves by searching for an individual hiding place from predators? However, the two Chilean biologists distinguish intelligence from the capacity to communicate through a system of more or less evolved signs, which in man (and in a small number of other species) become a symbolic language:

Due to the nature of the cognitive process and the function of the linguistic interactions, we cannot say anything about that which is independent of us and with which we cannot interact; $[\cdots]$ it follows that reality as a universe of independent entities about which we can talk is, necessarily, a fiction of the purely descriptive domain, and that we should in fact apply the notion of reality to this very domain of descriptions in which we, the describing system, interact with our descriptions as if with independent entities (Maturana \& Varela, 1980: 52-53).

Let us now briefly consider the second aspect of intelligence: the mental capacity to think. How can an agent communicate and act intelligently? What is intelligence? The hypothesis we make here is that (our) thought process constructs "mental models" of the world assumed to be formed in the mental sphere of individuals and which, though approximate, are indispensable for intelligent thought, being the basis for an understanding of reality and for interacting with other individuals. This hypothesis allows us to deduce that symbolic language represents the means for translating and communicating the mental models to other agents.

The psychologist Philip Johnson-Laird analyzed the cognitive function of mental models in his book Mental Models: Towards a Cognitive Science of Language, Inference and Consciousness (1983), an analysis that was taken up 
again in many of his subsequent works.

The psychological core of understanding, I shall assume, consists of having a "working model" of the phenomenon in your mind. If you understand inflation, a mathematical proof, the way a computer works, DNA, divorce, then you have a mental representation that serves as a model of an entity in much the same way as, say, a clock functions as a model of the earth's rotation ... Many of the models in people's minds are little more than high-grade simulations, but they are none the less useful provided that the picture is accurate (Johnson-Laird, 1983: 2-4).

Jay Forrester (1961) expressed in a similar vein this "mental model of a mental model":

The mental image of the world around us that we carry in our heads is a model. One does not have a city or a government, or a country in his head. He has only selected concepts and relationships, which he uses to represent the real system (Forrester, 1971: 213).

In The Fifth Discipline, Peter Senge deals with mental models on more than one occasion, emphasizing their role as conceptual tools on which our actions are based, presenting this definition:

"Mental models" are deeply ingrained assumptions, generalizations, or even pictures or images that influence how we understand the world and how we take action. Very often, we are not consciously aware of our mental models or the effects they have on our behavior. For example, we may notice that a co-worker dresses elegantly, and say to ourselves, "She's a country club person." About someone who dresses shabbily, we may feel, "He doesn't care about what others think" (Senge, 1990: 8).

Our "mental models" determine not only how we make sense of the world, but how we take action (Senge, 1990: 160).

Obviously, as they are produced "in the private sphere", mental models are not sufficient for effective thinking, revealing a clear limit: not only can they be imprecise and vague but also they are often erroneous.

Before Isaac Newton the prevailing mental model for gravity was, in simple words, that: "The apple breaking off from the branch falls toward the ground, attracted by the earth, following a trajectory directed toward the center of the globe." Newton changed the mental model of gravity as follows: "Apples are attracted to the earth as much as the earth is attracted to apples, following a trajectory determined by their mutual centers of gravity." Another prevailing mental model was: "All bodies in motion are destined to stop, unless a force intervenes to keep them in motion." Newton's First Law of Motion changed this mental model by introducing the principle of inertia: All bodies will continue moving in a uniform straight line (or remain still) unless some other force causes it to change this state." Another obvious erroneous mental model, which, un- 
fortunately, is widespread even today, even among educated persons, is the following: "When you have a cold your nose runs; I see that your nose is running, so I must stay away from you because I don't want to catch your cold." The logical mistake is clear as soon as we consider that my nose could be running because I have just finished crying my eyes out or because I suffer from hay fever (Mella, 2014a).

Moreover, the sense of the world that mental models express can be strongly influenced both by the opinions and beliefs on the world expressed by the thinking subject (Lippmann, 1922), often not even corresponding to an observable world (what about the Dante's "afterlife" model of Hell, Purgatory and Paradise), and by personal judgments often misleading (Senge, 1990).

The only feeling that anyone can have about an event he does not experience is the feeling aroused by his mental image of that event. That is why until we know what others think they know, we cannot truly understand their acts (Lippmann, 1922: 13).

Therefore, to make thinking more precise and suitable for action, man, from the time he became "sapiens", produced lexical and symbolic language to construct and communicate in a precise manner and to produce effective actions. One thing is certain: understanding, explaining, communicating and acting are not possible without the use of models (Mella, 2014b). Models are the tools of our intelligence, and I am convinced that intelligence can be thoroughly and operationally defined not as a simple cognitive process characterizing thought but as an aptitude, an "ability" to construct coherent and sensible models (Mella, 2012) in order to acknowledge, understand and communicate the world (and thus to pass the Turing Test); in particular, I believe that: intelligence is the ability to develop a system of coherent and meaningful models that allow us not only to survive in a world that is continually evolving but also to improve ourselves and make progress:

Intelligence may be conceived of as the ability to rapidly and efficiently construct or update the models of knowledge and arrange them into coherent "bodies of knowledge"; and to quickly learn to use them to survive in a changing world. Intelligent persons understand (and comprehend) quickly and effectively (Mella, 2012: 3).

Intelligent persons are those... who are not content to "look at the world with their eyes" (objects, facts, phenomena and processes) but who are able "to see the world with their minds" by constructing models to "understand" how the world is (description), how it functions (simulation), and how we can act as part of it (decision and planning), even without having the need, or possibility, of "looking at everything" (Mella, 2012: 3).

This capacity "to see" and not simply "look at" depends on the "ability" to construct models to understand, explain and simulate the world. Intelligent people quickly modifies his models after having observed the consequences of 
his actions in the world (Argyris 1993; Argyris \& Schön 1978, 1996; Sterman, 2000). For this reason intelligent persons have the "ability" (innate or acquired) to quickly construct, utilize and modify models; that is, to continually improve their knowledge; they are the ones who "see" the world in advance, who always "know" what is happening and what could happen, in order to deal with changes, control events and successfully face the various situations in their lives, deciding in the most rational way how to solve problems. If man wants to improve he (and organizations) must not only adapt but also develop a pro-active cognitive behavior, re-examining and changing the models that make up his knowledge, thereby anticipating change in the world. Mella's definition is in line with most of the definitions in the literature. For example, Jean Piaget stated:

Furthermore, intelligence itself does not consist of an isolated and sharply differentiated class of cognitive processes. It is not, properly speaking, one form of structuring among others; it is the form of equilibrium towards which all the structures arising out of perception, habit and elementary sensory-motor mechanisms tend. It must be understood that if intelligence is not a faculty, then this denial involves a radical functional continuity between the higher forms of thought and the whole mass of lower types of cognitive and motor adaptation; so intelligence can only be the form of equilibrium towards which these tend (Piaget, 2003: 7).

The following is an interesting definition of intelligence as behavioral and cognitive ability:

Individuals differ from one another in their ability to understand complex ideas, to adapt effectively to the environment, to learn from experience, to engage in various forms of reasoning, to overcome obstacles by taking thought. Although these individual differences can be substantial, they are never entirely consistent: A given person's intellectual performance will vary on different occasions, in different domains, as judged by different criteria. Concepts of "intelligence" are attempts to clarify and organize this complex set of phenomena (Neisser et al., 1996: 77-101).

Mella's definition contains, moreover, almost all of the 9 types of intelligence proposed by Gardner (1993, 1999), Social as well as Emotional intelligence; that is, the ability of an individual to specify his goals, intentions and emotions, and understand, interpret, and respond to the emotions of other individuals (Salovey, 2004). Some brief comments may be useful here.

Gardner wanted to emphasize that the "IQ Test" of intelligence does not fully account for all the types of intelligence, which, in different degrees, are found in every man. In fact, he holds that there are (at least) 9 types of intelligence: 1) Naturalistic Intelligence; 2) Musical; 3) Logical-Mathematical; 4) Existential; 5) Interpersonal; 6) Bodily-Kinesthetic; 7) Linguistic; 8) Intra-Personal; and 9) Spatial Intelligence.

Note that Gardner has never defined the concept of "intelligence" but has 
conceived of it as "a biopsychological potential to process information that can be activated in a cultural setting to solve problems or create products that are of value in a culture" (Gardner, 1999: 33). This represents one of the greatest limits of his proposal. The nine types of intelligence could be viewed as 9 abilities or aptitudes, which individuals in a collectivity each possess to a different extent.

Nevertheless, I hold that Mella's definition can be applied to all of Gardner's types of intelligence. Consider, for example, the Musical intelligence of musicians, orchestra directors, singers, who are able to "manage" every nuance of sound with instruments or their voice. What is musical intelligence, then, if not the "ability" to construct (composers), learn and repeat (performers) a model of sounds, pauses, rhythms, metrics, and so on? Observing an orchestra director, musician or singer before they begin their performance, we note that for some moments they close their eyes and "mentally repeat" the musical models that must guide them in their performance. I, too, know the songs and opera arias, but I cannot repeat them nor compose new ones. My Musical intelligence is almost non-existent.

If we observe a diver, gymnast, pole vaulter, ice skater, dancer, or any other athlete who must control the movements of his or her body, we realize that they are in fact able to produce a model of movements, a programed sequence of physical actions: constructing, learning and using their bodies to perform a model is at the heart of their Bodily-Kinesthetic intelligence. We are able to understand in this case as well by observing athletes, skaters, dancers, etc., who, before beginning their performance, mentally repeat the model to be carried out. And what about the Logical-Mathematical and Linguistic forms of intelligence? These are all based on formal mental models; and likewise for Naturalistic intelligence and any other form proposed by Gardner.

Even Social intelligence, which the psychologist Thorndike (1920) defines as "the ability to understand and manage men and women and boys and girls, to act wisely in human relations" and which represents a good basis for Turing's test and, in Gardner's schema, appears to correspond to Interpersonal intelligence, can be represented by Mella's definition, since Social intelligence is revealed as the capacity to create models of the physical and social environments which can guide man's behavior and enable him to exist.

\section{The Attribute of "Intelligent" Accompanies That of "Stupid". Carlo Cipolla's Test}

After this brief examination of intelligence as an attribute of thought, we shall take up the concept of intelligence from a pragmatic point of view: as an attribute of intelligent behavior as measured by the effects of social behavior in terms of the advantages and disadvantages it produces. We shall thus shift our focus from intelligent thinking to the intelligent behavior of man. In my view, this approach has great educational potential, since it can teach all of us, especially young people, a style of intelligent behavior. 
Before continuing, it is useful to note that in Turing's test no attempt was made to define the opposite of intelligence: an entity was either intelligent or non-intelligent. We owe to the excellent intuition of Carlo Cipolla, professor emeritus of economic history at the University of California, a truly "intelligent" intelligence test, formulated in the short "treatise" The Basic Laws of Human Stupidity, first printed in 1976 (as a Christmas gift for his friends) and later published in Italian in 1988, with translations in at least 13 languages. The treatise is well-known and has been commented on throughout the world (as testified to by the many sites dedicated to it). With an elegant style veiled with irony, Cipolla proposes a criterion to evaluate human behavior, not only those of people we regularly interact with in organizations (work, school, university, political parties, etc.), but also those we encounter only once by chance on the road, bus, public office and at the restaurant (and even though not originally conceived for this, the test might also be applied to animals).

To understand the features of Cipolla's intelligence test, we must keep in mind that Cipolla's true objective (as revealed by the title of his essay) was to discover a "filter" for the concept opposite to intelligence, which he defined as "stupidity". Therefore, Cipolla's test is now known as the "Stupidity Test", and it is applied to any type of "agent": individuals, couples, groups, organizations, public authorities, even sovereign nations.

In his pragmatic vision of "intelligence" as an attribute of human behavior, Cipolla starts from the assumption that intelligence and stupidity are not revealed all that much by the type of communicative behavior produced by a given agent. He considers the advantages and disadvantages produced as a consequence of the behaviors of the agent, which are "objectively" perceived and "evaluated by" an "observer" who qualifies these behaviors on the basis of two parameters (Figure 1):

1) Advantages (gains) or disadvantages (losses) to the agent (individual, group or organization)

2) Advantages (gains) or disadvantages (losses) for others (organization, collectivity, environment, etc.)

If we consider (1) and (2) as variables along two Cartesian axes (see Figure 1, quadrants a and (3), then we have obtained a "test" for discriminating between an intelligent and a stupid agent. An intelligent agent is one who, through his social behavior, simultaneously obtains advantages for himself and for other agents, A stupid agent is one who, though not gaining any advantage for himself from his behavior, even at times bringing harm to himself, at the same time harms others or stops them from having any type of advantage. These are wonderfully eloquent definitions.

Gains and losses may be recorded on the $\mathrm{X}$ and $\mathrm{Y}$ axis in dollars or francs, if one wants, but one has to include also psychological and emotional rewards and satisfactions as well as psychological and emotional stresses. These are intangibles and they are very difficult to measure according to objective standards (Cipolla, 2011: 16). 


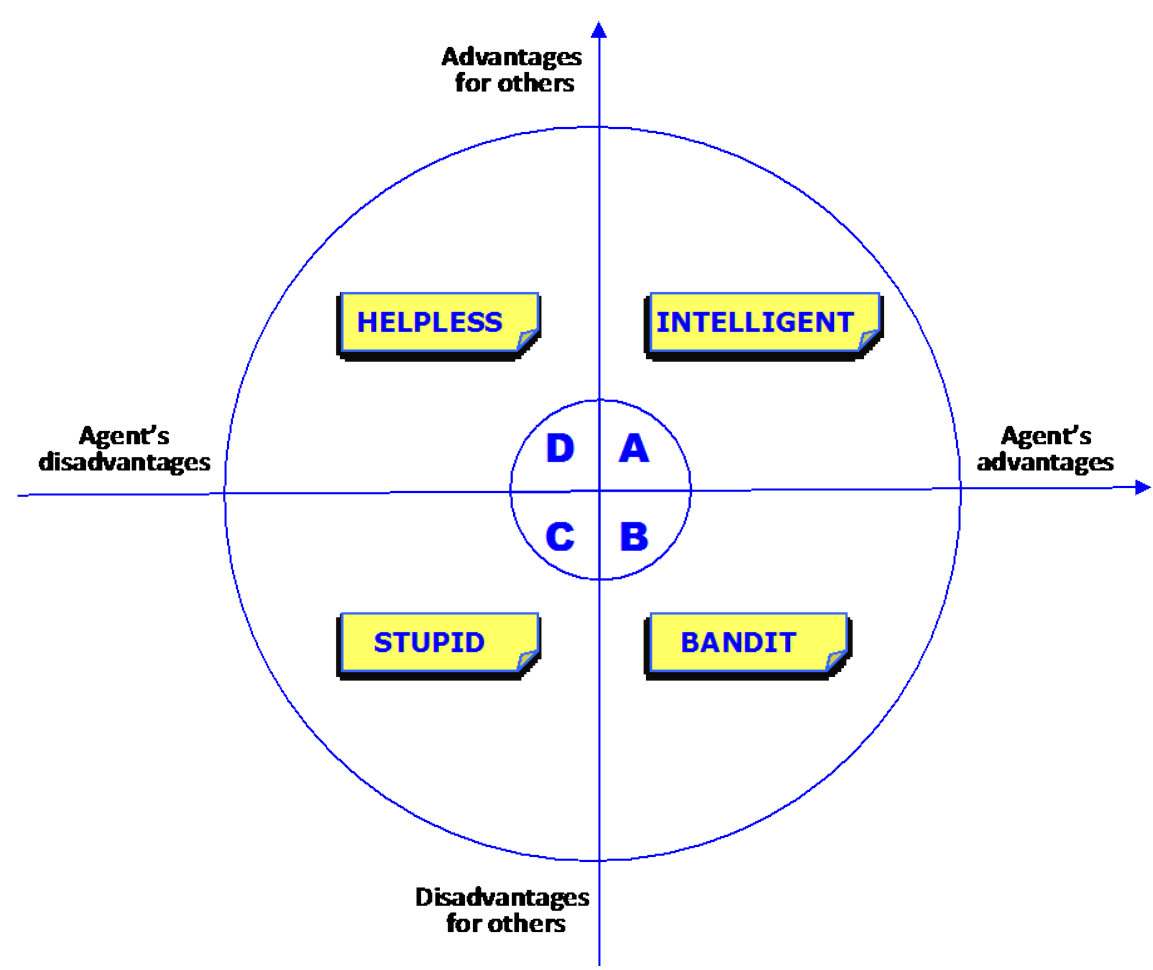

Figure 1. The four types of behavior in Carlo Cipolla's Test (Source: author's elaboration of Cipolla's Model).

The driver of the car in front of you on the highway is flanked by a slow-moving tractor-trailer truck, and this situation goes on for miles and miles, prohibiting you from passing the car. Is this driver intelligent? Obviously not. Is the politician who, in order to remain in power (personal advantage) drafts a good policy (advantages for others), a stupid individual? No, just the contrary. Several people in a theater continue talking during a play, not paying attention to what is happening on the stage (personal disadvantage), thereby stopping others sitting near them from following the play (harm for others). Are they intelligent or stupid? Is the subversive who damages the property of others, thereby producing among the general public an aversion against his cause and damaging his movement, intelligent or stupid? The "Test for stupidity" goes as follows: does the person who harms you harm himself as well? Yes! Then he can be defined as Stupid. Are you trying to gain advantages for yourself and at the same time procure benefits for others? Yes! Then you are Intelligent. Obviously this is an infallible test if applied from the point of view of the evaluating subject.

A broad class of agents revealing intelligent behavior are competing companies who, to obtain profits in a competitive environment (personal advantage), are forced to improve the quality of their products, and perhaps even lower their prices, thereby favoring innovation and employment (advantages for consumers and society), as illustrated in Adam Smith's famous observation:

It is not from the benevolence of the butcher, the brewer, or the baker, that we can expect our dinner, but from their regard to their own interest. By 
directing that industry in such a manner as its produce may be of the greatest value, he intends only his own gain, and he is in this, as in many other cases, led by an invisible hand to promote an end which was no part of his intention. Nor is it always the worse for the society that it was not part of it (Smith, 1776: 456).

A large class of stupid agents are those who act only "on principle", thereby frustrating the work of others without gaining any personal benefits, as often occurs in board meetings, on faculty or departmental committees, in political parties, assemblies with unanimous voting regulations, even in international associations of nations when a nation vetoes a proposition "based on principle".

Cipolla's formidable intuition is not limited to defining intelligent and stupid behavior; it also leads to two other, opposite types of behavior: that of the bandit and the helplessagent. For Cipolla, a bandit is an agent who, to gain personal advantage, causes harm to others. Prototypical bandits are thieves (in the broad sense), businessmen who, having gained a monopolistic position, exploit this to raise prices without updating their products, or speculators that swindle their clients. Finally, the helpless agent is one who, in order to produce advantages for others, ends up harming himself, for example, those who sacrifice their lives for others, heroes, missionaries, or someone who gives up his parking place and waits a long time for a new one to materialize.

The four quadrants produced when we consider parameters (1) and (2) as Cartesian axes allow us to identify the four individual types, presented in simplified form in Figure 1:

1) Intelligent people. An intelligent person is one who voluntarily acts to gain advantages for himself, and for this reason produces advantages for others as well. To gain more advantages the intelligent person must also continually increase the advantages for others.

2) Bandits. These are people who, in order to gain advantages, willingly cause harm to others and who, in order to increase their advantages, procure even greater harm to others. However, this increase in the harm to others leads such disadvantaged individuals to react in a way that gradually reduces the bandits' advantages.

3) Stupid people. The opposite of the intelligent person is the stupid one, who, in order to deny advantages to others, voluntarily damages himself and is willing to suffer even greater damage even though this may increase the damage to others: "A stupid person is a person who causes losses to another person or to a group of persons while himself deriving no gain and even possibly incurring losses" (Cipolla, 2011: 17).

4) Helpless (Naïve) people. Such people willingly choose to damage themselves in order to provide others with advantages, going even so far as making the supreme sacrifice of giving up their lives to benefit others. The sacrifice diminishes the greater the benefit to others becomes.

Thus, Cipolla's Test has a wide field of application, since it allows us to judge 
others' behavior in relation to the four types of behavior mentioned above.

\section{The Laws of Human Stupidity}

Carlo Cipolla attempts to determine the percentage of stupid people-which he indicates by the symbol " $\sigma$ " - in a given population. To determine if " $\sigma$ " depends on education or on the social circle of the agent, Cipolla conducted a "lighthearted" experiment that entailed dividing the population of his University into four groups: school custodians, students, clerks and teachers in order to determine the percentage of stupid people, " $\sigma$ ", in each group. Surprisingly, he found that " $\sigma$ " remained constant for all the groups. Enthusiastic about his discovery, he extended his research to a group of Nobel Prize winners; here, too, he found, "happily", that this population had the same " $\sigma$ " of stupid individuals. Based on this "lighthearted" experiment, he arrived at his first conclusion:

The probability that a certain person be stupid is independent of any other characteristic of that person (Cipolla, 2011: 11).

He found it extraordinary that nature succeeds in maintaining constant the percentage of stupid individuals no matter what population is being considered. Concentrating his astute attention on the results of these experiments, Cipolla presents several "Basic laws on human stupidity" which, using my own generalizations and interpretations, can be summarized as follows (I shall only briefly describe these without analyzing them):

1) Stupidity is inevitable. In all places, times and groups there has also been and will always be a percentage " $\sigma$ " of stupid agents; in his book A Short Introduction to the History of Human Stupidity, the philosopher Walter Pitkin (1934) estimated that four people out of five are stupid enough to be called "stupid"; that amounts to over four billion today;

2) Stupidity cannot be quantified. No matter hard we try to quantify the number of stupid individuals, their number will always be greater than the one we have come up with;

3) It is not possible to recognize the stupid individual. Stupidity can be found in the simple as well as the educated person; in the worker and the businessman; adults and children; citizens or rulers. We cannot recognize the stupid person from his appearance but rather from the consequences of his behavior.

People whom one had once judged rational and intelligent turn out to be unashamedly stupid. Day after day, with unceasing monotony, one is harassed in one's activities by stupid individuals who appear suddenly and unexpectedly in the most inconvenient places and at the most improbable moments (Cipolla, 2011: 12).

4) Stupidity is reflexive. All of us can show stupid behavior intermixed with other types of behavior. Often when we judge others as being stupid we are unaware that we may have the same characteristic. 
5) The stupid person is more dangerous than the bandit (Cipolla, 2011: 28); The latter harms others but at least procures advantages for himself, while the stupid individual produces only disadvantages, for himself and for others; in effect stupid people do not know they are stupid, and that is one more reason why they are extremely dangerous;

Non-stupid people always underestimate the damaging power of stupid individuals. In particular, non-stupid people constantly forget that at all times and places and under any circumstances to deal and/or associate with stupid people infallibly turns out to be a costly mistake (Cipolla, 2011:31);

6) The decline of a nation begins when the number of stupid individuals (and, I might add, also the number of bandits) exceeds that of the intelligent citizens.

Carlo Cipolla must have been amused by his lucid analysis. In fact, the essay that, in Italy, presents his theory-together with other essays full of irony-is titled "Allegro ma non troppo" ("Cheerful But Not Too Much"). However, his test is truly powerful and convincing, especially owing to his decision to focus the analysis on the most deleterious form of social behavior, stupidity, thereby confirming Albert Einstein's conviction: "Two things are infinite: the universe and human stupidity; and I'm not sure about the universe".

Unfortunately, rational persons have great difficulty in understanding the modus operandi of those we can define as stupid since, in carrying out their actions, stupid individuals are not guided by any form of rationality, and for this reason their behavior is not only harmful to the interests of others but also self-damaging.

Cipolla's definition of stupidity is not the only possible one. Stupidity can be associated with cognitive limitations; the American Heritage Dictionary (2013) associates these characteristics to "stupidity": "1) Slow to learn or understand; obtuse. 2) Tending to make poor decisions or careless mistakes. 3) Marked by a lack of intelligence or care; foolish or careless: a stupid mistake. 4) Dazed, stunned, or stupefied. 5) Pointless; worthless: a stupid job". Mats Alvesson and André Spicer adopt the concept of "Functional Stupidity" to analyze the cognitive aspects of organizations: "Functional stupidity refers to an absence of reflexivity, a refusal to use intellectual capacities in other than myopic ways, and avoidance of justifications" (Alvesson \& Spicer, 2012: 1194). Nevertheless, these and other definitions of stupidity do not detract from the validity of the Cipolla's tests I have presented. However, more than referring to Cipolla's Test, these last few definitions appear more to complete Mella's definition of intelligence by indicating that stupidity is the incapacity to construct, utilize and modify models on which knowledge and behavior are based.

\section{The Social Wheel}

Cipolla's model is complete in itself. Nevertheless, it can be expanded by considering that he does not explicitly consider the voluntariness of an agent's behavior. I therefore propose a further generalization of the Stupidity Test by intro- 
ducing together with the following two variables:

1) Advantages (gains) or disadvantages (losses) to the agent.

2) Advantages (gains) or disadvantages (losses) for others a third variable as well.

3) The volition or lack thereof of the actor to cause advantages to others.

In this way we can add four other types to Cipolla's original typology, as shown in Figure 2:

1) Able or capable agent. An able or capable agent is one who, in order to gain an advantage, produces advantages to others as well, even though unintentionally.

2) The egoist. This individual gains advantages for himself and, without thinking about it, damages others in the process.

3) Incapable agent. The opposite of the able person is the incapable one, who damages himself and, without being aware of it, others as well.

4) The meritorious person. The opposite of the egoist is the worthy individual, who, without considering the consequences, damages himself in order to produce advantages for others.

If the first two parameters, (1) and (2), are indicated as Cartesian axes in Figure 1 and the third parameter, (3), contains axes with the same origin but rotated by 45 degrees to form 8 sectors rather than four, in order to admit the four new types, then the eight types of social behavior can be shown in the sectors of a hypothetical "social wheel" representing a test to evaluate behavior and the subjects that manifest such behavior (Figure 2).

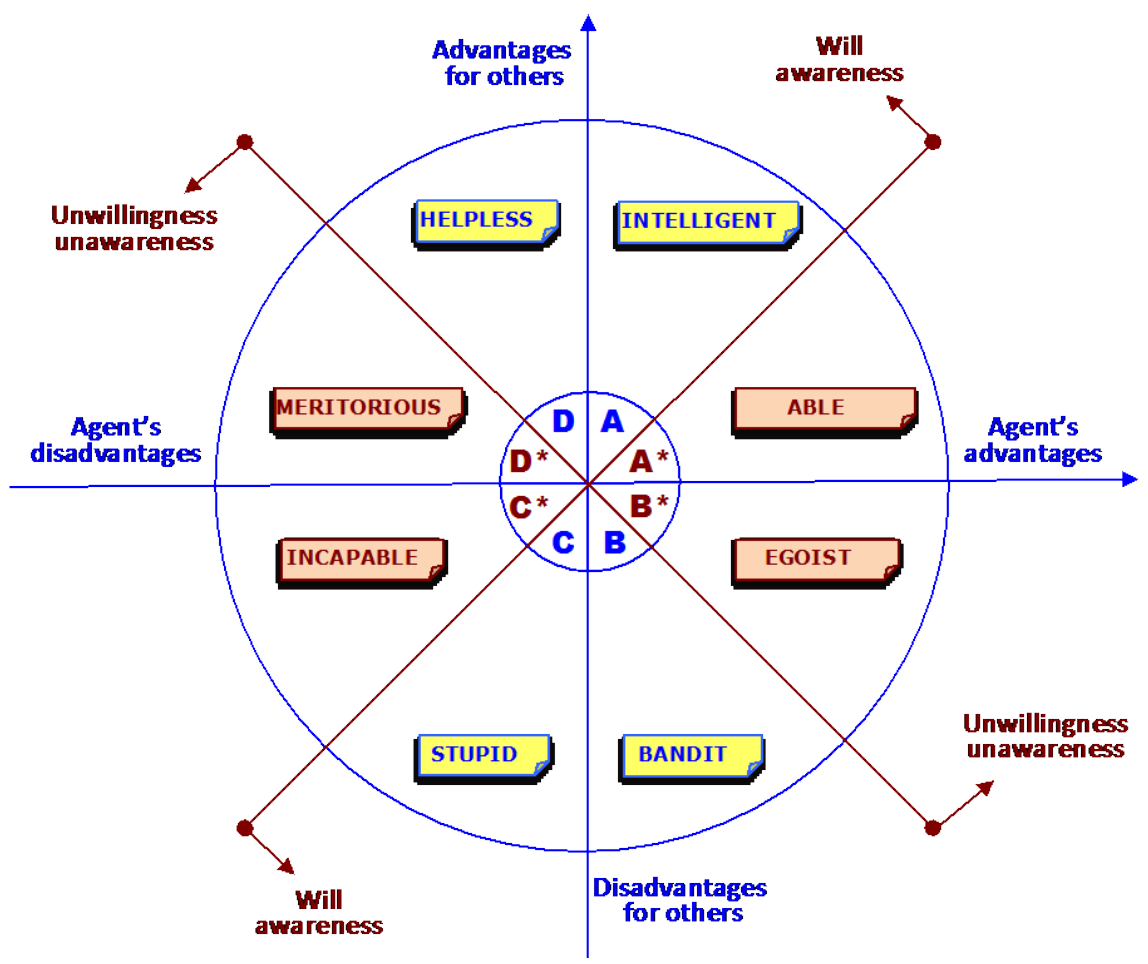

Figure 2. The social wheel (Source: author's elaboration). 
Unfortunately, it is not possible to use the social wheel a priori; I believe that Law 3 of stupidity: 3 . it is not possible to recognize the stupid individual", can be generalized for all 8 characteristics of the "social wheel": 3-bis. it is not possible to recognize the character of an individual (stupid, incompetent, intelligent, able, etc.) simply by knowing his profession, educational qualifications, family traits, etc.; stupidity, incompetence, ability, etc., can be found in the simple as well as in the educated person; in the worker and the businessman; adults and children; citizens or rulers. We cannot recognize the type of person from his appearance but rather from his behavior.

The surgeon who, to avoid error, goes over all the phases of the operation beforehand (operational model) and then properly carries out his job is an "able" person. The researcher who voluntarily dedicates himself to researching new cures and then experiments with these on patients to try and save them from diseases which, up until then, had been incurable, is intelligent. People who have a "myopic" vision and choose based only on individual, short-term interests, without considering the long-term effects or those on society as a whole, are classified as selfish. On the other hand, those who act based on their own interests even while aware they are harming others are classified as bandits.

The teacher who, in order to make it easier for himself at lessons, prepares excellent slides that aid the students in learning and allows them to get better grades on their exam, is not behaving as an Intelligent person but merely as a capable teacher. Is the captain of a sinking ship who is the first to abandon the vessel in an attempt to save only himself, without considering that the other passengers will thus be left without any assistance, a Bandit or an Egoist? A large class of egoists are those free-riders who appropriate larger and larger shares of the common resources for their personal benefit, thereby producing a Tragedy of the Commons (Hardin, 1968). The soldier who, in order to maintain his own position, sacrifices his life, not knowing that this will allow his companions to save themselves, is not a helpless person but a meritorious one. The player who skips workouts and as a result plays poorly in games, thereby contributing to his team's defeat, is not stupid as much as he is incapable.

\section{Conclusion}

Is it possible to teach children, students, teachers, managers, or anyone how to be intelligent? If we accept the definition of intelligence as the ability to understand the world by constructing meaningful models, as the capacity to construct and quickly use those models to react and be pro-active, then the answer is "Yes!".

Turing's test is not sufficient in this regard, since it defines intelligence as the capacity of an "entity" to interface linguistically with us-perhaps through an interpreter-thereby revealing the elaboration of mental models by that "entity" which are not distinguishable from human ones, including the capacity to commit errors. What happens, however, if we interface with an entity that is capable 
of constructing models which are different from ours but much more powerful and not translatable into human models, so as to be beyond the pale of human understanding? Would we define this entity as unintelligent?

The role of educational systems is fundamental for developing the ability to quickly construct coherent models, modify the system of models already acquired, and use them in our life processes. The educational system must combine the thousands of models contained in the dozens of books the students must study for while at school with effective instruments to teach them how to connect these models, and above all how to gain the capacity to create new models that can explain the interconnections among objects and variables and examine the dynamics of the world and understand its complexity; it is therefore necessary to add to the normal curricula tools that develop Systems Thinking and teach us how to recognize the links among objects and the interactions among variables; instruments such as differential equations, the principles of Systems Thinking and the techniques and simulations offered by system dynamics (Forrester, 1961), together with the instruments to recognize and manage complexity and chaos.

Systems Thinking is one of the most powerful tools of knowledge and understanding because it teaches us to devise coherent and sense-making models of the world, which are among the most effective for improving our intelligence, modifying our world and constructing our existence (Mella, 2015: 595).

The most powerful and effective models are the systems ones that view reality as a set of connected and dynamic parts forming a whole. An understanding of the connection between the parts and the whole and their dynamics is the fundamental characteristic of operational and creative intelligence (Mella, 2015: 595).

If we consider the other aspect of intelligence, as an attribute of human activities which are evaluated by observing the advantages and disadvantages they cause the agent and those the agent interacts with, the answer is still "Yes!".

Cipolla's Test and the broader framework of the "Social Wheel" should be viewed as powerful teaching tools to be included in the educational programs of every country. These two models are very simple, as they do not make use of abstractions, and present a clear advantage: they can be applied to all social, political and organizational contexts and, being based on behavior, have two undeniable advantages:

The first is that it defines a person (and that person's behavior) as stupid (or intelligent, or hapless, or a bandit) on the basis of facts; or, at least, on our understanding and definition of facts. The second, and even more important, is that it leads us to concentrate on the vital factor: not stupidity per se, but the damage it causes (Livraghi, 1996).

As we have seen in Section 4, in presenting his "laws of human stupidity" Ci- 
polla emphasizes:

5. The stupid person is more dangerous than the bandit (Cipolla)

Since the bandit, while causing damage to others, obtains advantages for himself, while the stupid person produces disadvantages for himself and for others.

However, the "Social Wheel" leads to an even more drastic and sad law:

5-bis. The incapable agent is more dangerous than the stupid one (Mella)

Since he disadvantages himself and others without even being aware of his own incapacities. Moreover, the stupid person can transform himself in a short time into an intelligent person. The incapable person needs time to become conscious of his incapacity and even more time to change his behavior. Stupidity is not handed down to others; at most it contaminates other people, increasing the number of stupid persons. On the other hand, incapacity breeds more incapacity, thereby increasing over time the number of incapable people who unconsciously will produce more and more damage to society. Government leaders should reflect on this fact when they design educational systems and choose educators, keeping in mind that "the incapable educators are the most dangerous producers of incapacity".

I hope the "social wheel" gives pause for reflection and, if possible, rotates in the right direction. For this reason, it is to be hoped that everyone can be educated to behave intelligently and capably, thereby avoiding stupidity and incompetence.

Using the Social Wheel as an educational instrument is not difficult; nor does it require complicated and costly interventions. For example, starting in middle school and high school, and all the way up to university, it would be quite simple for a teacher to organize a quick seminar to present the background concepts in both Cipolla's and Mella's models. Students could be invited to find examples of each type of behavior and given the possibility to reflect on their own ways of interacting with others. In my opinion, the students themselves would divulge to their friends and family the messages those models easily transmit. As an alternative, since it is customary for teachers to assign readings and research to their students so that they will not be inactive over the summer holidays, it would not be difficult for them to suggest reading an e-book with Cipolla's essay and the extensions proposed in the present paper.

Finally, I wish to note that this conceptual paper is not without its limitations, two in particular. It presents three relatively autonomous arguments: the presentation of some definitions of intelligence, an examination of the framework proposed by Cipolla, and an attempt to extend his framework by proposing "The Social Wheel" model. Even if these parts are linked together in a single line of reasoning, each on its own deserves more in-depth treatment, which is not possible here, that includes psychology, behavior is mand, above all, pedagogy and sociology. Nor was it possible to refer to the vast literature on artificial intelligence to explore how Turing's Test and Mella's definition of intelligence are 
suitable as well to this field of engineering:

Artificial intelligence is a rapidly evolving field of engineering with an ultimate objective to build machines capable of acting and thinking like human beings. The early phase of $\mathrm{Al}$ was concerned with developing programs for theorem proving and game playing. Modern AI encompasses various tools and techniques for humanlike reasoning, learning, planning, language and pattern recognition (Kumar, 2008: 1).

\section{Acknowledgements}

This short essay is dedicated to the memory of Carlo Cipolla, professor emeritus at the University of California, founder and first dean (1964-1967) of the Faculty of Economics at Pavia University (Italy), who was my professor of Economic History and later my colleague and friend.

\section{References}

Alvesson, M., \& Spicer, A. (2012). A Stupidity-Based Theory of Organizations. Journal of Oral and Maxillofacial Surgery, 49, 1195-1220.

https://doi.org/10.1111/j.1467-6486.2012.01072.x

American Heritage Dictionary (2013). (The) of the English Language. Houghton Mifflin Harcourt Publishing Company.

Argyris, C. (1993). Knowledge for Action. A Guide to Overcoming Barriers to Organizational Change. San Francisco, CA: Jossey Bass.

Argyris, C., \& Schöon, D. (1978). Organizational Learning: A Theory of Action Perspective. Reading, MA: Addison Wesley.

Argyris, C., \& Schöon, D. (1996). Organizational Learning II: Theory, Method and Practice. Reading, MA: Addison Wesley.

Cipolla, C. (2011). The Basic Laws of Human Stupidity. Bologna: Il Mulino Ed.

Forrester, J. W. (1961). Industrial Dynamics. Waltham, MA: Pegasus Communications.

Forrester, J. W. (1971). Counterintuitive Behavior of Social Systems (Collected Papers of J. W. Forrester, pp. 211-244). Cambridge, MA: Wright-Allen Press.

Gardner, H. (1993). Multiple Intelligences: The Theory in Practice. Basic Books.

Gardner, H. (1999). Intelligence Reframed: Multiple Intelligences for the 21st Century. Basic Books.

Gregory, R. L. (1987). The Oxford Companion to the Mind. Oxford: Oxford University Press.

Hardin, G. (1968). The Tragedy of the Commons. Science, 162, 1243-1248. https://doi.org/10.1126/science.162.3859.1243

Jefferson, G. (1949). The Mind of Mechanical Man. British Medical Journal, 1, 1105-1110. https://doi.org/10.1136/bmj.1.4616.1105

Johnson-Laird, P. (1983). Mental Models: Towards a Cognitive Science of Language, Inference, and Consciousness. Cambridge, MA: Harvard University Press.

Kihlstrom, J. F., \& Cantor, N. (2000). Social Intelligence. In R. J. Sternberg (Ed.), Handbook of Intelligence (2nd ed., pp. 359-379). Cambridge: Cambridge University Press. https://doi.org/10.1017/CBO9780511807947.017 
Kumar, E. (2008). Artificial Intelligence. New Delhi: I. K. International Publishing House.

Lippmann, W. (1922). Public Opinion. New York, NY: Hartcourt Brace.

Livraghi, G. (1996). The Power of Stupidity.

http://serendip.brynmawr.edu/serendipia/Stupidity.html

Maturana, H. R., \& Varela, F. J. (1980). Autopoiesis and Cognition. The Realization of Living. Boston: Reidel Publishing. https://doi.org/10.1007/978-94-009-8947-4

McFarland, D., \& Bösser, T. (1993). Intelligent Behavior in Animals and Robots. Cambridge, MA: MIT Press/Bradford Books.

Mella, P. (2012). Systems Thinking. Intelligence in Action. New York, NY and Berlin: Springer Verlag. https://doi.org/10.1007/978-88-470-2565-3

Mella, P. (2014a). The Magic Ring. Systems Thinking Approach to Control Systems. New York, NY and Berlin: Springer Verlag.

Mella, P. (2014b). The Pillars of Learning, Understanding, Studying and Explaining. Creative Education, 5, 1615-1628. http://www.scirp.org/journal/ce

Mella, P. (2015). Give Me an Arrow and I Will Construct a World for You. Creative Education, 6, 594-611. https://doi.org/10.4236/ce.2015.66059

Mingers, J. (1995). Self-Producing Systems: Implications and Applications of Autopoiesis. New York, NY: Plenum Press. https://doi.org/10.1007/978-1-4899-1022-6

Neisser, U. et al. (1996). Intelligence: Knowns and Unknowns. American Psychologist, 51, 77-101. https://doi.org/10.1037/0003-066X.51.2.77

Piaget, J. (1950). The Psychology of Intelligence. London: Routledge.

Pitkin, W. B. (1934). A Short Introduction to the History of Human Stupidity. New York, NY: Simon\&Shuster.

Salovey, P., Brackett, M. A., \& Mayer, J. (2004). Emotional Intelligence: Key Readings on the Mayer and Salovey Model. Port Chester, NY: Natl Professional Resources Inc. https://doi.org/10.1017/CBO9780511806582.019

Senge, P. (1990). The Fifth Discipline: The Art and Practice of the Learning Organization (2nd ed. 2006). New York, NY: Doubleday/Currency.

Smith, A. (1776). An Inquiry into the Nature and Causes of the Wealth of Nations. In P. J. R. Perry, \& T. H. Von Laue (Eds.), As Reproduced in Sources of the Western Tradition (Vol. 2, pp. 133-134). Boston: Houghton Mifflin Company. https://doi.org/10.1093/oseo/instance.00043218

Sterman, J. D. (2000). Business Dynamics: Systems Thinking and Modeling for a Complex World. New York, NY: McGraw-Hill/Irwin.

Thorndike, E. L. (1920). Intelligence and Its Use. Harper's Magazine, 140, 227-235.

Turing, A. M. (1950). Computing Machinery and Intelligence. Mind, 59 (236), 433-460. https://doi.org/10.1093/mind/LIX.236.433 